\title{
Research Ethics Capacity Building in Sub-Saharan Africa: A Review of NIH Fogarty-Funded Programs 2000-2012
}

\author{
Paul Ndebele, \\ Medical Research Council of Zimbabwe (Zimbabwe) \\ Douglas Wassenaar, \\ University of KwaZulu-Natal (South Africa) \\ Solomon Benatar, \\ University of Cape Town (South Africa) \\ Theodore Fleischer, \\ University of Cape Town (South Africa) \\ Mariana Kruger, \\ Stellenbosch University (South Africa) \\ Clement Adebamowo, \\ University of Ibadan (Nigeria) \\ Nancy Kass, \\ Johns Hopkins Bloomberg School of Public Health (USA) \\ Adnan A. Hyder, and \\ Johns Hopkins Bloomberg School of Public Health (USA) \\ Eric M. Meslin \\ Indiana University School of Medicine (USA)
}

\section{Abstract}

The last fifteen years have witnessed a significant increase in investment in research ethics capacity development throughout the world. We examine nine research ethics training programs that are focused on Sub-Saharan Africa and supported by the US National Institutes of Health. We collected data from grants awards' documents and annual reports supplemented by questionnaires completed by the training program directors. Together, these programs provided long-term training in research ethics to 275 African professionals, strengthened research ethics committees in 19 countries in Sub-Saharan Africa, and created research ethics curricula at many institutions and bioethics centers within Africa. Trainees' leadership resulted in new national systems and policies on research ethics, human tissue storage and export, and methods of monitoring compliance with research ethics guidelines. Training programs adapted to challenges that arose due to varied trainees' background knowledge in ethics, duration of time available for training, spoken and 
written English language skills, administrative obstacles, and the need to sustain post-training research ethics activities. Our report showcases the development of awareness of research ethics and building/strengthening of basic research ethics infrastructure in Sub-Saharan Africa. Nevertheless, the increasing amount and complexity of health research being conducted in SubSaharan Africa suggests the need for continued investment in research ethics capacity development in this region. This paper is part of a collection of papers analyzing the Fogarty International Center's International Research Ethics Education and Curriculum Development program.

\section{Keywords}

bioethics; capacity building; research ethics; Sub-Saharan Africa

In November 1999, the African Malaria Vaccine Testing Network (AMANET) sponsored a seminar on health research ethics in Africa in Arusha, Tanzania, to identify the needs, priorities, structures, and processes for research ethics review and monitoring of research in Sub-Saharan Africa (SSA). Reports by country representatives revealed several problems with the review and monitoring of research including inadequately functioning research ethics committees (RECs), lack of resources, limited or outdated legislation, overworked research ethics committee members, low levels of awareness of research ethics guidelines, and lack of personnel trained in bioethics and research ethics (Rugemalila \& Kilama, 2001). These realities were confirmed by other authors who also reported the nonexistence of RECs in some countries and institutions, under resourcing of RECs, and lack of formal research ethics training among REC members as well as the fact that only a handful of trained bioethicists worked in the region (Milford, Wassenaar, \& Slack, 2006; Nyika et al., 2009).

This lack of adequate resources for research ethics, coupled with the increasing volume of health research in Sub-Saharan Africa, was thought to be contributing to increased vulnerability to exploitative research (Angell, 1997; Benatar, 2002; Isaakidis et al., 2002; Rugemalila \& Kilama, 2001; Singer \& Benatar, 2001). Investments in research in Africa were disproportionate to the almost complete absence of investment in research ethics. Despite the increasing demand for research ethics expertise, no Sub-Saharan African institution had developed and implemented graduate-level training in research ethics.

At the same time, the US National Bioethics Advisory Commission (NBAC) completed its study of ethical issues in international research (NBAC, 2001), which included two specific recommendations directed at US research sponsors: (1) develop and implement strategies that assist in building local capacity for designing, reviewing, and conducting clinical trials in developing countries; and (2) build the capacity of RECs in developing countries to conduct scientific and ethical review of international collaborative research.

\section{FINANCIAL RESOURCES FOR RESEARCH ETHICS CAPACITY BUILDING}

The global research ethics landscape has expanded considerably since the NBAC study conducted in 1999. Between 2000 and 2012, the Fogarty International Center (FIC) invested approximately US\$33 million in research ethics capacity development worldwide. Of this 
amount, approximately $40 \%$ (US $\$ 13$ million) specifically supported capacity building in Sub-Saharan Africa (personal communication, Barbara Sina, Fogarty International Center, National Institutes of Health). Other FIC training programs (e.g., the AIDS International Training and Research Program [AITRP] and the Medical Education Partnership [MEPI]) also supported research ethics training, which suggests that this figure underestimates FIC spending on research ethics capacity in Africa.

The Wellcome Trust, a UK charity, has spent an estimated UK£2million (US\$3.1 million) since 2007 (with numerous additional grants prior to 2007) to support bioethics research, research ethics training, and workshops in developing countries. Approximately UK£1.2 million was focused on ethics projects in SSA (personal communication, Katherine Littler, Wellcome Trust). Between 2005 and 2011 the European Developing Countries Clinical Trials Partnership (EDCTP) invested over $€ 3.2$ million (US\$4 million) in 54 research ethics projects in Africa (personal communication, Nuraan Fakier, EDCTP). Several other institutions and agencies (e.g., World Health Organization, UNAIDS, African AIDS Vaccine Programme, Family Health International, US Department of Health and Human Services Office for Human Research Protections [OHRP], US NIH Department of Bioethics) also conducted or sponsored mostly short-term research ethics training activities in SSA during this period.

We review research ethics capacity building efforts by FIC-sponsored programs in SubSaharan Africa between 2000 and 2012. We reflect on the achievements in order to have insight into successes and failures, and identify current needs and gaps as well as future requirements.

\section{Methods}

We focus on nine FIC funded programs that had at least one long-term trainee from SubSaharan Africa (WHO/ AFRO region) and existed for at least one four-year funding cycle between 2000 and 2012. FIC defines a long-term trainee as someone trained for three months or more working toward an academic certificate, diploma, master's, or doctoral degree. Qualitative and quantitative data were collected from a review of grants award documents and programs' annual reports. In addition, a 17-item questionnaire was administered by face-to-face discussions and e-mail to the program directors to obtain information on the structure, approach, content, and mentoring aspects of their training programs. In addition, information was collected on the achievements and challenges that the programs have faced (see Appendix A). A separate paper assesses the achievements and challenges of individual trainees from these Africa-focused training programs (Ali, Hyder, \& Kass, 2012).

\section{Results}

The programs that recruited long-term trainees from SSA are presented in greater detail. The section also highlights the achievements and challenges faced by the nine programs. 


\section{PROGRAMS THAT FOCUSED ON SUB-SAHARAN AFRICA}

During the first year of the program (2000-2001), FIC awarded two planning grants to two institutions from Sub-Saharan Africa and five ethics training grants that focused on training scholars from Sub-Saharan Africa. The five training grants were awarded to Johns Hopkins University, University of Toronto, Case Western University, University of Cape Town, and the Universities of Pretoria and KwaZulu-Natal. In 2004, three additional awards were made to support SSA trainees at University of North Carolina at Chapel Hill, University of Ibadan, Nigeria, and both Michigan State University and University of Malawi. In 2008, a new award was made to Indiana University in partnership with Moi University, Kenya (Meslin, Were, \& Ayuku, 2013). Six of these nine programs remain funded beyond 2012. This review excludes awards for North Africa or the Middle East region, which are covered in a separate paper (Silverman et al., 2013). We present key information on the nine programs in Table 1.

The majority of countries from which trainees have been drawn are characterized by low levels of socioeconomic development as evidenced by low GDP per capita and limited expenditure on health. The countries range from 13 to 65 on the Corruption Perceptions Index (CPI), which provides an estimate of perceived corruption in the public sector (a scale of zero represents the highest level of corruption while a score of 100 represents the least corrupt). Table 2 summarizes the social and economic indices for the countries. All the countries except for Namibia had clinical trials that were registered in www.clinicaltrials.gov.

\section{DESCRIPTIONS OF THE PROGRAMS}

From 2001, the Johns Hopkins Fogarty African Bioethics Training Program (FABTP, 2000-2017) selected three trainees per year from any African country for one year of bioethics and research ethics training (Hyder et al., 2007; Ali et al., 2012). Training activities focused on four core concentration areas: theories and principles of ethics, teaching of research ethics, empirical research in research ethics, and research ethics committees. The trainees first spent six months at Johns Hopkins University in Baltimore, Maryland, for training in research methodology, observation of medical and public health institutional review boards (IRBs), completion of graduate school-level academic and intensive bioethics courses, and intensive mentoring. Trainees then returned to their home countries for a funded, mentored six-month practicum. Starting in 2010, FABTP changed its model to focus on developing African institutional ethics capacity instead of individuals, with the aim of building sustainable ethics centers. FABTP competitively selected one African institution with existing strengths in bioethics each year to help the institution deepen its research ethics capacity.

The International Research Ethics Training Program (IRETP 2000-2016) based at Case Western Reserve University in Cleveland, Ohio, provided long- and short-term training in research ethics for participants from Nigeria and Uganda, as well as the post-Communist countries of Romania, the Russian Federation, and Tajikistan. The program supported: (1) a master's degree program for trainees from each of the countries; (2) a short course in research ethics in each country; (3) faculty from each of the collaborating countries visited 
Case Western Reserve University to facilitate mid- and senior-level faculty development in research ethics; (4) in-country consultation; (5) an electronic ethics training repository for information, protocols, and projects; (6) a semi-annual electronic newsletter; and (7) webbased activities to facilitate ongoing education in research ethics and continuation of a trainee network. This program no longer includes an African focus.

The University of Toronto developed a Master of Health Science-Bioethics International Stream (UTMBIS 2000-2012), which selected trainees with the potential to make an impact in research ethics in their home countries. The program trained individuals from West Africa and South Asia. According to the grant proposal and annual reports, the trainees completed the program in two components over 24 months. During the University of Toronto component, trainees completed eight courses and a research practicum in general bioethics or international research bioethics to earn a master's degree in bioethics. During the home country component, trainees conducted mentored projects to integrate newly acquired skills into leadership, research, and teaching at their home institutions.

The International Research Ethics Network of Southern Africa (IRENSA 2000-2011) provided a one-year graduate diploma program at the University of Cape Town, South Africa, consisting of three two-week intensive modules (Research Ethics: Philosophical, Professional, and Legal Perspectives; Research on Human Subjects in a Cross-Cultural Context; Global Health, Public Health Ethics, and Public Health Research Ethics). According to the grant proposal and annual reports, the program was open to candidates from all over Africa and trained 97 mid-career professionals with diverse professional backgrounds from South Africa and eight other African countries, where they were involved in the conduct, monitoring, oversight, funding, or regulation of research or expressed specialized interest in research ethics. This program closed in 2011, but was replaced by ARESA (Advancing Research Ethics Training in Southern Africa) at Stellenbosch University.

The South African Research Ethics Training Initiative (SARETI 2000-2017) is a multidisciplinary program leading to a master's degree in Health Research Ethics, originally based on a collaboration between the Universities of Pretoria and KwaZulu-Natal, with input from Johns Hopkins University. According to the grant proposal and annual reports, SARETI sponsored four master's degree candidates each year from 17 African countries as well as 18 nondegree long-term trainees. The core curriculum consisted of: (1) 10 months of modular coursework at the partner institutions; (2) practical work with research ethics committees (RECs); (3) attendance at two intensive US-based bioethics courses at Johns Hopkins Berman Institute of Bioethics and Georgetown University; and (4) a research-based dissertation on a topic of relevance to strengthening health research ethics at the trainee's home institution, leading to submission of a paper to a peer-reviewed journal.

The West African Bioethics Training Program (WABTP 2004-2016) takes advantage of resources at the University of Ibadan and the Dominican Institute, Nigeria, to offers a master's degree program, six-week diploma courses, on-site and off-site short certificates, and refresher courses in both English and French to researchers, REC members, and administrators primarily from Nigeria and some from other West African countries. In 
addition, WABTP offers modules in scientific integrity, good clinical practices, good laboratory practices, grant writing, and pedagogy, and organizes public lectures and symposia to increase awareness of bioethics in West Africa.

The Strengthening Bioethics Capacity and Justice in Health (SBCJH 2004-2012) is a collaborative partnership between the University of North Carolina (USA) and University of Kinshasa in the Democratic Republic of the Congo (DRC). Four fellowships for six-months of mentored ethics research, social science methodology, IRB training, and curriculum development at University of North Carolina were offered to trainees. The program trained a core group of African health professionals who were subsequently supported and mentored to conduct in-country workshops, teach, provide consultation, create curriculum, publish studies, enhance REC capacity, and develop national ethics guidelines.

The Training for Scholarships in Research Ethics program (TSRE 2004-2009) was a collaborative arrangement between Michigan State University and the College of Medicine at the University of Malawi. The program recruited six scholars from Malawi, Tanzania, and Zimbabwe for 18 months of intensive training in research ethics and related social science disciplines, designed to produce independent scholarship in research ethics. Scholars spent six months at Michigan State University taking formal courses and creating a research proposal. After six months, the scholars moved to the College of Medicine, University of Malawi, to take courses for a certificate or master's in Public Health with a specialty in Bioethics. All scholars were expected to submit a manuscript to a peer-reviewed journal.

The Indiana University-Moi University Academic Research Ethics Partnership (IU-Moi AREP 2008-2017) is a curriculum development and training initiative built on a twodecades-long partnership between the two universities (Tierney et al., 2013). IU-Moi AREP has developed two master's degree programs: a new concentration in International Research Ethics within the MA in Philosophy at Indiana University in Indianapolis and a MHSc. in International Health Research Ethics in the Department of Behavioural Sciences at Moi University in Eldoret, Kenya. While both master's programs enroll students independently, they share key curricular components, use joint advisory committees, engage common bioethics-trained faculty as mentors, use similar dissemination plans, and utilize harmonized evaluation strategies. For example, both programs have a year-long required practicum that includes a minimum of six weeks of coursework, lectures, and hands-on experiences at the counterpart university. In addition, topic-based short courses and an annual Teaching Skills in International Research Ethics (TaSkR) workshop rotate between the two universities to provide short-term training opportunities to other interested students and faculty.

\section{Training Program Attributes}

To allow for comparison of the key attributes of the nine programs, Table 3 provides a summary of the training program attributes.

\section{TRAINING PROGRAM FORMATS}

All nine programs aimed to build research ethics capacity, but differed with regard to content, pedagogy, program requirements, mentoring strategy, and format (see Table 3). Six 
programs were multi-institutional collaborations that included training components conducted at another institution, such as workshops, practicum experiences, or summer schools, while three were single institution programs. Six programs offered certificate-level training, two offered diploma-level training, and seven offered master's degree-level training. While Fogarty grants did not directly support $\mathrm{PhD}$ training, two programs (SARETI and SBCJH) managed to secure additional support and graduated four trainees with PhDs. Seven programs offered short duration workshops that reached over 300 individuals. Six programs reported that they introduced major changes to their programs, based on initial experience, including revision of program requirements, such as additional modules or reading materials, development of new outcomes (e.g., MPH degree), amendment of admission criteria, strategies to address gender disparities, and revised partnerships/ consortia arrangements.

\section{LANGUAGE OF INSTRUCTION}

All nine programs used English for instruction. Two of these programs, which operated at least in part in French-speaking countries, used both English and French.

\section{TRAINING COMPONENTS}

All nine programs reported focusing primarily on research ethics. Seven programs reported including bioethics and public health; and four reported including some focus on clinical/ medical ethics. Seven programs included background philosophy (also covering African philosophy) as a core element; all nine programs included research ethics as a core element. Some programs reported covering specialized topics such as the ethics of HIV vaccine trials, community engagement, and professional ethics. All programs reported that they had included instruction in various aspects of Responsible Conduct of Research, consistent with NIH requirements,

All programs reported involving face-to-face interaction; one program reported including an online learning component. Four of the programs reported that they required trainees to submit a dissertation, and a similar number reported that they required trainees to submit or publish a paper in a peer-reviewed journal. Two programs reported that they provided reentry grants to all their trainees, and one program reported that it provided reentry grants to only a subset of trainees. Some of the reentry grants were used for conducting empirical studies, while some used them for establishing or strengthening existing research ethics committees in their institutions.

\section{MENTORSHIP}

Eight programs provided a structured system of mentoring. For these programs, mentoring expectations were defined without regard to timing and reporting. Five of nine programs reported that they relied on unstructured mentoring. For the eight programs that had structured mentoring, trainees were assigned to mentors, and mentors engaged in continued contact with their trainees throughout the period of learning and afterwards. In one program, resources were provided for mentors to visit trainees at their home institutions. During such visits, the mentors could facilitate workshops, present seminars, and engage in teaching or other activities aimed at enriching the trainee's home institution. Another program (IU-Moi 
AREP) uses a paired-mentor approach in which students have a mentor at their home institution and a practicum mentor at the counterpart institution to provide regular interaction and assistance in completing site-specific portions of the students' research program.

\section{TRAINING IN CULTURAL ASPECTS OF BIOETHICS}

All nine programs included training components on cultural values, for example by having a course, required readings, or seminars dedicated to cultural issues in research or other forms of orientation including visits to communities or cultural sites. Multiple activities taught trainees the importance of culture and cultural differences and their relevance to research and research ethics. For example, one program had a community engagement component during which trainees were expected to spend a week with community members learning about their culture. Some programs also invited community representatives to give talks to students on cultural issues. In one program, students were expected to write an essay on a research experience involving an ethical dilemma around a cultural issue. They were to describe their views at the time they experienced the dilemma and their views after having gone through some training modules. Some concepts and ideas that were considered to be potentially helpful in making progress toward resolving cross-cultural dilemmas in international research ethics were developed into a formal text that was used to explore such issues with participants in the IRENSA and JCB programs (Benatar, 2004).

Long-term Trainees-During the period 2000-2012, the nine programs trained 275 longterm trainees from 19 Sub-Saharan African countries (of the 49 countries in the region) (Table 4). Fourteen of the 19 trainee countries now have five or more returned trainees, nine countries are home to 10 or more trainees, and three of the most populous countries in SubSaharan Africa—Kenya, Nigeria, and South Africa—have even larger numbers. The highest number of scholars came from South Africa (76) and Nigeria (72). The two countries were host to training programs.

Across the nine programs, long-term trainees received different types of training and for different durations: $23 \%$ were trained at a certificate level; $42 \%$ at a postgraduate diploma level (professional qualification that is below master's degree level); $34 \%$ at the master's level; and 2\% at the doctoral level (Table 5). Seven programs reported having a duration of one year, while one reported having a duration of six months and another reported a duration of 18 months. All programs recruited individuals who had at least a first-level university degree and were involved in work that was relevant to research ethics. Overall, $42 \%$ of trainees were female. Only the IRENSA program recruited more female trainees than male (58\% or 56 out of 97 trainees).

Achievements of FIC African Programs-The achievements identified from the training programs were classified using the framework for research ethics system evaluation proposed by Hyder et al. (2009).

National and Regional Strategies-The programs identified various impacts that they believed their trainees had made on national and regional research ethics policies. Graduates 
helped craft national research ethics guidelines, developed some of the first policies for storage and export of tissue samples in Africa, provided input to revise national laws guiding the conduct of research, and implemented methods to monitor clinical research. Some trainees took positions of national leadership or were appointed to national bodies (Kass, Hyder, \& Ali, 2013). One received a presidential award for contributions to research ethics (SARETI, 2004). At the regional level, substantial networking among program graduates was identified. For example, FIC trainees spearheaded the creation of the African Association of Research Ethics Committee Administrators (AAREC, 2011), where all the executive committee members and the majority of members were former FIC trainees. This network keeps research ethics administrators in Africa updated on best practices in running an REC. Other programs also directly support networking; for example, at the end of each of the two four-year funding cycles, SARETI arranged open Africa Health Research Ethics Symposia for trainees to share scholarly work and ethics review experiences. Two FIC graduates serve as coordinators of the Mapping African Research Ethics Committees project (MARC; IJsselmuiden et al., 2012). This project also has an FIC/SARETI-funded social networking component to facilitate consultation and debate among research ethics stakeholders in Africa. Several Fogarty trainees participated in the writing of a research ethics guidebook for African members, a project known as SAREN and funded by EDCTP. This book will be freely available on the Web in pdf format in 2014 .

Research Ethics Review-Since 2000, Sub-Saharan Africa has witnessed a dramatic increase in professionals who have received NIH/FIC-supported long-term training in research ethics (Table 4). Many former trainees serve on institutional and national RECs, frequently as chairs, deputies, or secretaries; some entered programs with this experience as well. For example, graduates from the IRENSA program serve on more than 40 RECs in Southern Africa, although many of them were serving on RECs previously. Several programs organized regional REC capacity building workshops. Some trainees developed institutional guidelines and policies for research ethics committees, which are often the first relevant documents to guide the conduct of the REC.

African Publications in Research Ethics-Many programs reported that their trainees have published work in refereed journals; more detail of this is provided elsewhere (Kass, Hyder, \& Ali, 2013; Fix et al., 2013). Some programs have also published papers that describe their specific accomplishments and challenges (Ali et al., 2012; Hyder et al., 2007; Upshur, 2008; Meslin, Were, \& Ayuku, 2013). Faculty and trainees from one program published a paper on research ethics committees in Africa that has been widely cited (Kass et al., 2007).

Institutional Commitment-Several trainees are building new bioethics centers or are heads of existing centers. For example, in Zimbabwe, the secretariat for the national REC is led and staffed by Fogarty trainees from two programs, while at University of Botswana, University of Zambia, and Makerere University, Fogarty program trained individuals are spearheading the establishment of Centers of Bioethics. In one instance (IU-Moi AREP) trainees and the site PI received institutional support to establish a Center for Bioethics and resource library at the university. 
Based on the credibility granted to them by their programs, trainees carved out niches that have allowed them to play an active role in building research ethics capacity and, in some cases, to make bioethics a vital part of their careers. For example, some trainees hold academic positions in which they lead research ethics courses and training, or serve in influential positions in government organizations that conduct, regulate, or monitor research. In response to their new skills, new positions have been created in some institutions to accommodate the newly trained graduates. For example, IRB Administrator and Regulator positions were created in Botswana and Zimbabwe respectively. Programs have thus led to the development of research ethics career paths and furthered the institutionalization of research ethics careers in many African institutions for at least some of the trainees. Not all trainees were able to find positions in research ethics and many resumed their previous positions. There were a few trainees who went back to their old positions and engaged in a very minimal amount of research ethics work.

Researchers' Conduct-Some programs have taken the lead in educating undergraduates and graduates, contributing to a cohort of future researchers with more background in research ethics. The programs have developed curricula, trained researchers and REC members, conducted seminars and workshops, developed institutional and national research ethics guidelines, developed or contributed to online training modules (including African Malaria Network Trust [AMANET] and Training and Resources in Research Ethics Evaluation [TRREE]) for REC members and researchers, and contributed faculty to existing programs. Several FIC program graduates serve as trainers in research ethics, thereby producing a ripple effect.

We believe that these are transformative contributions that could have been made only by programs and trainees with high levels of skills and knowledge. Collectively these nine programs have effected a dramatic change in the research ethics landscape in Sub-Saharan Africa universities. Other trainees are using their skills outside of academia, in the medical insurance industry, the military, nongovernmental organizations, and at research centers (Kass, Hyder, \& Ali, 2013).

\section{CHALLENGES}

Discussions with program directors and analysis of questionnaires revealed a number of common and some unique obstacles.

Trainee Preparedness-Programs identified several factors that potentially limited trainee performance including: wide disparities in trainee academic skills and background knowledge (some lacked any exposure to the topics covered, others lacked sufficient skills in using laptop computers or performing online literature searching); time constraints, such as difficulties in obtaining sufficient time off work to fully engage in the training; and difficulty with language, especially when English was the trainee's second language. Four of the nine programs reported that some of their trainees experienced language-related challenges; such trainees were mainly from Francophone countries and other non-Englishspeaking African countries. These four programs found ways of assisting such trainees so that they could fulfill program requirements. As a result of this challenge some programs 
introduced informal tests for fluency in spoken and written English. In at least two programs, the inability of some students to conduct online literature searching led to the establishment of formal training sessions by a university librarian, which has now been adopted for all trainees.

Administrative Problems-Administrative problems included: increased costs in the face of decreasing or constant budgets; exchange rate fluctuations; delayed access to funding occasioned by local administrative incapacity; difficulties in coordinating between collaborating institutions; problems in arranging international travel and visas; and irregular or inadequate Internet connections that hindered communications and research. Most of these administrative challenges were resolved as the programs matured. Through networking, Program Directors were able to rely on their colleagues, both within the Fogarty network and outside of the network among colleagues with other global training program experience, for assistance in resolving some challenges.

Obstacles to Training at Some African Institutions-Some of the programs, particularly those located in politically unstable countries, faced unique challenges such as: social unrest necessitating schedule changes and preventing trainees from finishing their programs within the stipulated time frame; bureaucratic challenges (e.g., obtaining the correct visa for visiting a US-based institution, scheduling a visa interview in the host country); and changes in institutional and national leadership. Some programs disbursed individual research grants in tranches only upon receipt of progress reports. Some programs reported trainees who did not complete their training (especially the research component).

Post-training Issue-Some former trainees encountered problems after returning home due to: limited opportunities to apply their new knowledge and skills at their home institutions; political tensions around status, especially where RECs were traditionally headed by senior professors who were not suitably trained; and pressure of daily work at their home institution causing delays in progress with post-training ethics assignments. New trainees were sensitized to these issues to prepare them for better reentry to their home institutions. Programs reported difficulties in tracking some trainees after they returned home. Due to limited availability of funds and other resources in home institutions, some former trainees also faced the challenge of sustaining research ethics-related activities. However, some trainees acquired small grants from EDCTP and other funders to support post-training activities. Some programs changed recruitment criteria in order to address these challenges. For example, many required a letter of institutional commitment.

Program Critique-There has been some criticism that these training programs have served US purposes by colonizing the minds of Africans with Western notions of research ethics (Schüklenk, 2000). It should be noted, however, that cross-cultural dimensions were prominent aspects of teaching in all of the programs. Several programs highlight relevant aspects of African indigenous value systems in ways that enrich research ethics, maximize local sensitivity and relevance, and, less importantly, offset the allegation that the FIC programs uncritically export the US IRB model to Africa (Chadwick \& Schüklenk, 2006). 
Gender Balance-Achieving gender balance in programs was not easy: all but two programs failed to achieve the goal of equal numbers of male and female trainees (Table 5), though one of them has since achieved this balance in its incoming cohorts.

Despite these challenges, no program was prematurely ended or required major revision as a result of the problems encountered. Program activities continued even in cases where external forces, such as social instability, seriously disrupted training. Program directors adapted to changing and often unwelcome circumstances. Annual network meetings for program directors as well as the support provided by FIC were essential in facilitating adaptation. Most programs have been able to renew their funding after their initial 4-5 years and made changes to improve training and mitigate problems encountered.

\section{Discussion}

The experiences of the nine programs over a decade represent a substantial and successful investment of human and financial resources to benefit research ethics capacity in Africa. In general, it is clear that research ethics capacity has increased, that measurable outputs can be identified, and that the ethics landscape has changed positively. It is important to highlight that both quantitative and qualitative data are available to document the difference created by these programs. One paper in this journal specifically deals with the papers published by FIC trainees as well as the achievements of individual trainees (Fix et al., 2013). There is evidence (see NIH CareerTrac) to suggest that many FIC graduates assumed positions of relevance to research ethics at both institutional and national levels.

Regarding gender balance, it is possible that the majority of programs could not achieve gender balance because mid-career women in Africa are often not able to take substantial amounts of time (minimum six months) away from home due to family commitments to attend a training program. This could also be explained by the mere fact that maledominated institutions may be less likely to nominate women. The program that trained more women than men likely did so because on-campus attendance was limited to three two-week periods throughout the academic year.

Regarding the observation concerning the differences in the number of trainees by country, the high demand for training in South Africa and Nigeria may be a result of changes in the legal systems in these two countries, which now require such training (Nigeria Federal Ministry of Health, 2007; South African Department of Health, 2004; South African Parliament, 2003). In South Africa, for example, the new Health Act makes it mandatory for all research with human participants to be reviewed by a registered REC and all REC members are required to receive initial and ongoing training. Countries with the fewest trainees included Burkina Faso, Mali, Namibia, and Togo, which have relatively small populations. Most of the remaining Anglophone African countries with no FIC trainees appear to conduct little clinical research (see ClinicalTrials.gov).

To address the challenge of a small number of trainees who fail to complete their program requirements on time, better methods of selecting quality trainees are needed, with more objective selection criteria and priority given to candidates who already hold positions of 
relevance in their home institutions, for example, REC administrators and REC members, and better post-training networking and support.

Sustainability is a concern for all capacity development programs. A sustainable program is one that is capable of creating local demand and operating without FIC funding. The bioethics programs have been sensitive to this issue from the beginning and many have incorporated activities to assist with sustainability from inception. Vital to this has been a common approach of "institutionalizing" the programs and their outputs within universities and institutes in Africa. Strategies range from programs run out of African institutions, to working with specific institutions to enhance their bioethics capacity, to encouraging institutions to use the "products" of these programs, for example, as consultants or members of RECs. It is important that the process of institutionalization continues since it is only when strong research ethics capacity exists within the major research institutions of the continent that sustainability will be achieved. The strengthening of African institutions' capacity does not mean that there would be no role for colleagues from outside Africa; rather the nature and type of assistance should evolve from basic to advanced training and mentoring, with outsiders serving as consultants and peer reviewers.

It is of concern that to date there is little evidence of indigenous African investment in research ethics capacity development, for example, through grants and university support. It is therefore pertinent to ask whether Africa values this field, acknowledges the need for research ethics capacity, and when it will invest in it. This is a critical question not only for policy support and integration with current priorities but also for sustainability. African governments, academia, development organizations, and even the private sector need to explore this area and make it one of their priorities. The implicit measure of such priority setting is investment. This does not mean that all the needed investments for bioethics and research ethics capacity should come from within Africa; but it does mean that some African funds should flow into capacity development for bioethics. This is also important to ensure that such training processes remain relevant to the ethics issues in Africa (Tangwa, 2002).

Although not directly supported by the data presented in this paper, it is also important to note that more African countries have developed legal frameworks that formalize ethics review requirements, following, for example, the direction provided by Nigeria and South Africa, where ethics review is now a legal requirement for all health research. The absence of legal support for research ethics requirements in many countries limits the rights of research participants (Andanda et al., 2011) and the impact that training research ethicists can make.

\section{Study Limitations}

The following limitations with respect to this study are worth highlighting:

1. Self-reported data from program directors, much of which was in their grant proposals or annual progress reports, which may have overplayed success and underplayed challenges.

2. No direct data from trainees. 
3. Self-reported data from program directors, even if completely accurate and unbiased, was based on what they thought was important to report. If one PI mentioned something and another one did not, it does not necessarily mean that the second one did not experience the same success or challenge but it simply was not mentioned.

4. Potential recall bias.

\section{Best Practices}

Externally funded research ethics training programs should remain an important part of the ethics training landscape in Africa as the number of clinical trials being conducted in Africa rises steadily. There is a clear need for continued investment in Africa-based research ethics leadership and curriculum development to sustain and grow the significant cohort of longterm trainees that FIC-funded programs in Africa have graduated. Training programs must become embedded into local institutions and funding should progressively be sought from local sources. Curricula should in part be sensitive to local issues and value systems and should be published for wider scrutiny and debate to identify effective models and practices and to share resources. African-based programs could better work together to facilitate coordination, referrals, and sharing of resources. Exchanges of students and resource persons between training programs would promote development generally and improve cross-cultural awareness.

\section{Research Agenda}

Ongoing and detailed follow-up of trainees and their career paths is required to inform current and future training programs, In addition, all trainees in externally funded training programs should be required to publish work on issues relevant to their training and research ethics practices or environment, to continue the building of Africa-based research ethics knowledge and scholarship that the nine FIC programs described in this paper have significantly accelerated (see Fix et al., 2013). Attention also needs to be paid to identifying, developing, and describing possible career paths for research ethics graduates because research ethics remains a "part-time" commitment in many African settings.

\section{Educational Implications}

It is clear that these initiatives need to continue. It is also clear that because of the activities described in this paper, Africa now has a growing base of skilled graduates to offer undergraduate research ethics training and short courses that were previously only offered by visiting experts from developed countries. While specialist advisers and consultants from developed countries will always be required, they should no longer be required for basic and introductory research ethics training, which is increasingly being offered by FIC-sponsored graduates. The cohort of FIC-funded research ethics graduates described in this paper has generated a new demand for PhD-level education, to further build African capacity for leadership, skills, and scholarship in this field. 


\section{Conclusion}

The FIC-funded programs have contributed significantly to research ethics capacity in Africa. The programs are a storehouse of resources for syllabi and teaching methods that could be adapted for use in other programs. Yet gaps still exist. For example, some countries have no or very few people trained in research ethics, and some RECs are still working with untrained administrators. With the growing demand for persons trained in research ethics, there is a need to continue with capacity development so as to meet this demand. In the medium term, a goal worth considering would be to have a Fogarty graduate in each of the over 161 African RECs identified by MARC to date (IJsselmuiden et al., 2012). There also needs to be an increased focus on building institutional capacity, for example, including bioethics in undergraduate and postgraduate courses, and creating and officially recognizing bioethics or research ethics units. The ultimate goal should be to ensure self-sustainability of current programs so that they can continue beyond Fogarty funding by becoming embedded in local institutions and attracting sufficient self-supported applicants to support the program. In order to reach this point, more advanced training is needed at the master's level. The fact that several individuals have acquired $\mathrm{PhDs}$ in research ethics-related areas after completing FIC-funded training is evidence of the need for research ethics training at higher levels. Doctoral training programs and postdoctoral opportunities need to be created so as to address the emerging demand. The few individuals who have been trained at the doctoral level have assumed positions of leadership in Sub-Saharan Africa. Doctoral and postdoctoral training will contribute to the much-needed leadership in research ethics on the African continent.

\section{Acknowledgments}

We are very grateful to the Program Directors of all nine Fogarty programs described in this paper who responded to our questionnaire in a timely manner. We also extend our gratitude to program support staff in the nine programs for coordinating the collation of data and Fogarty NIH staff for coordinating data collection and other logistics. We are also grateful to Drs. Barbara Sina and Joe Millum for helpful comments on our manuscript. We thank the Fogarty International Center of the National Institutes of Health for supporting the Research Ethics capacity building grants described above.

\section{References}

AAREC. First African Conference for Administrators of Research Ethics Committees (AAREC) report. 2011. Retrieved fromwww.healthresearchweb.org/files/AARECFinalReport.pdf

African Malaria Network Trust (AMANET). Basic research ethics course. Retrieved from http:// kie.georgetown.edu/nrcbl/documents/sylb/se0604.pdf

Ali J, Hyder A, Kass N. Research ethics capacity development in Africa: Exploring a model for individual success. Developing World Bioethics. 2012; 12(2):55-62. [PubMed: 22708713]

Andanda P, Awah P, Ndebele P, Onigbogi O, Udatinya D, Mwondela M. The ethical and legal regulation of HIV-vaccine research in Africa: Lessons from Cameroon, Malawi, Nigeria, Rwanda and Zambia. African Journal of AIDS Research. 2011; 10(4):451-463.

Angell M. The ethics of clinical research in the Third World. New England Journal of Medicine. 1997; 337(12):847-849. [PubMed: 9295243]

ARESA. Advancing Research Ethics Training In Southern Africa. http://sun025.Sun.Ac.Za/portal/ page/portal/Health_Sciences/English/Centres\%20and\%20Institutions/Bioethics1/ARESA

Benatar SR. Justice and medical research: A global perspective. Bioethics. 2001; 15:333-340. [PubMed: 11697389] 
Benatar SR. Towards progress in resolving dilemmasin international research ethics. Journal of Law, Medicine and Ethics. 2004; 32(4):574-582.

CareerTrac (NIH). https://careertrac.niehs.nih.gov/about.gsp

Case Western Reserve University. Electronic ethics training repository for information, protocols, and projects. Retrieved from http://globalconnectre.org/

Chadwick R, Schüklenk U. Editorial. Developing World Bioethics. 2006; 20(1):iii.

Fix J, Odell J, Sina B, Meslin E, Goodman K, Upshur R. A bibliometric analysis of an international research ethics trainee program. Journal of Empirical Research on Human Research Ethics. 2013; 8(5):75-81. [PubMed: 24384518]

Hyder A, Harrison R, Kass N, Maman S. A case study of research ethics capacity development in Africa. Academic Medicine. 2007; 82(7):675-683. [PubMed: 17595564]

Hyder A, Dawson L, Bachani AM, Lavery J. Moving from research ethics review to research ethics systems in low-income and middle-income countries. Lancet. 2009; 373:862-865. [PubMed: 19269523]

IJsselmuiden CB, Marais D, Wassenaar DR, Mokgatla-Moipolai B. Mapping African ethical review committee activity onto capacity needs: The MARC initiative and HR Web's interactive database of RECs in Africa. Developing World Bioethics. 2012; 12:74-82. [PubMed: 22512919]

Isaakidis P, Swingler GH, Pienaar E, Volmink J, Ioannidis JPA. Relation between burden of disease and randomised evidence in Sub-Saharan Africa: A survey of research. British Medical Journal. 2002; 324:702-705. [PubMed: 11909786]

Kass N, Hyder A, Ajuwon A, Appiah-Poku J, Barsdorf N, Elsayed D, et al. The structure and function of research ethics committees in Africa: A case study. PLoS Medicine. 2007; 4(1):e3. [PubMed: 17253898]

Kass, N.; Hyder, A.; Ali, J. Evaluating the impact of Fogarty African bioethics capacity building initiatives: A preliminary analysis. Fogarty International Research Ethics Training Program Network Meeting, Fogarty International Center, National Institutes of Health; Bethesda, MD: 2013.

MARC. Mapping African Research Ethics Capacity. www.researchethicsweb.org/

Meslin EM, Were E, Ayuku D. Taking stock of the ethical foundations of international health research: Pragmatic lessons from the IU-Moi Academic Research Ethics Partnership. Journal of General Internal Medicine. 2013; 28:639-645.

Milford C, Wassenaar DR, Slack CM. Resources and needs of research ethics committees in Africa: Preparations for HIV vaccine trials. IRB. 2006; 28(2):1-9. [PubMed: 16770882]

National Bioethics Advisory Commission. Ethical and policy issues in international research: Clinical trials in developing countries. 2001. Retrieved from http://bioethics.georgetown.edu/nbac/clinical/ Vol1.pdf

Nigeria Federal Ministry of Health. National code of health research ethics. Abuja, Nigeria: FMOH; 2007. Retrieved from www.nhrec.net/nhrec/NCHRE_10.pdf

NIH FIC. AIDS International Training and Research Program. Retrieved from www.fic.nih.gov/ Programs/Pages/hiv-aids.aspx

NIH FIC. Medical Education Partnership Initiative (MEPI). Retrieved from www.fic.nih.gov/ Programs/Pages/medical-education-africa.aspx

Nyika A, Kilama W, Chilenge R, Tangwa G, Tindana P, Ndebele P, Ikingura J. Composition, training needs and independence of ethics review committees across Africa: Are the gate-keepers rising to the emerging challenges? Journal of Medical Ethics. 2009; 35(3):189-193. [PubMed: 19251972]

Rugemalila JB, Kilama WL. Proceedings of the seminar on health research ethics in Africa. Acta Tropica. 2001; 78:S1-S126. [PubMed: 11403005]

SARETI. Newsletter. 2004. Retrieved from http://sareti.ukzn.ac.za/Libraries/Newsletters/ SARETI_Newsletter_2003.sflb.ashx

Schüklenk U. Protecting the vulnerable: Testing times for clinical research ethics. Social Science and Medicine. 2000; 51:969-977. [PubMed: 10972439]

Silverman H, Edwards H, Shamoo A, Matar A. Enhancing research ethics capacity in the Middle East and North African Region: Experience and challenges of a Fogarty-sponsored training program. 
Journal of Empirical Research on Human Research Ethics. 2013; 8(5):40-51. [PubMed: 24384515]

Singer PA, Benatar SR. Beyond Helsinki: A vision for global health ethics- Improving ethical behaviour depends on strengthening capacity. British Medical Journal. 2001; 322(7289):747. [PubMed: 11282846]

South African Department of Health. Ethics in health research: Principles, Structures and processes. Pretoria: South African Department of Health; 2004.

South African Parliament. National Health Act No. 61 of 2003. Pretoria: Government Printers; 2003.

Tangwa G. The traditional African perception of a person: Some implications for bioethics. Hastings Center Report. 2002; 50:39-43.

Tierney WH, Nyandiko WN, Sika AM, Wools-Kaloustian K, Sidle JE, Kiplagat J, et al. "These are good problems to have...": Establishing a collaborative research partnership in East Africa. Journal of General Internal Medicine. 2013; 28(Suppl 3):S625-638. [PubMed: 23797916]

TRREE. Training and Resources in Research Ethics Evaluation. http://elearning.trree.org/

Upshur R. Building research ethics capacity in developing world contexts: The University of Toronto Joint Centre for Bioethics experience. Special Issue. Journal of Academic Ethics. 2008; 6(4):271275.

Wellcome Trust. International ethics grants awarded. Retrieved from www.wellcome.ac.uk/Funding/ Ethics-and-society/Funded-projects/Awards-made/WTDV030188.htm

\section{Biographies}

Paul Ndebele currently serves as Director of the Medical Research Council of Zimbabwe. His research interests include research ethics, health research regulation, and professional integrity. He coordinated the writing of this paper from inception, study tool development, data collection and analysis, and writing and approval of final version.

Douglas Wassenaar is Professor of Psychology in the School of Applied Human Sciences at the University of KwaZulu-Natal. He is the Director of the South African Research Ethics Training Initiative (SARETI). His main interests are in research ethics. He contributed in various ways in the work reported in this paper including; development of the framework, writing and approval of final version.

Solomon Benatar is Emeritus Professor of Medicine at University of Cape Town. His research interests include healthcare systems, research ethics, professional integrity, global health, and global health ethics. He contributed data about the IRENSA program (as PI) and worked on all drafts leading to this final submission.

Theodore Fleischer serves as Deputy Director of the University of Cape Town Bioethics Centre and Senior Lecturer in Bioethics in the Medical Faculty and Senior Lecturer in Law in the Faculty of Law at UCT. He has research interests in bioethics, law, and research ethics. He contributed in various ways to this publication, including development of the framework, data analysis, and writing and approval of the final submission.

Mariana Kruger is the co-director of SARETI and her main interest is the institutionalizing of ethics review committees and children as research participants. Her role in this issue was to assist in designing the questionnaire to collect the data, as well as providing the SARETI data. 
Clement Adebamowo is Director of the West African Bioethics Training Program and Chairman of the Nigerian National Health Research Ethics Committee. His research interests are ethics of genomics research, noncommunicable diseases epidemiology, and surgical oncology. He contributed to drafting the manuscript and approved the final content.

Nancy Kass is an Associate Director of the Johns Hopkins Berman Institute of Bioethics. She is Co-Director of the Fogarty Africa Bioethics Training Program. She participated in development of the paper framework, first draft of the paper, and the review of subsequent drafts.

Eric M. Meslin is a professor at Indiana University School of Medicine. He also serves as Director of the Indiana University Center for Bioethics. He participated in the development of the paper framework, the first draft and review of subsequent drafts, and approved the final version.

Adnan A. Hyder is a Professor of International Health and Director of Health Systems in the Department of International Health at Johns Hopkins Bloomberg School of Public Health; and Associate Director of Global Bioethics at the Johns Hopkins Berman Institute of Bioethics. He is Co-Director of the Fogarty Africa Bioethics Training Program and helped develop the first draft of the paper and reviewed subsequent drafts.

\section{Appendix 1. SUB-SAHARAN AFRICA WRITING PROJECT}

Questionnaire for PIs for describing program and content

NOTE: Majority of questions require Yes/No answers. The questions highlighted in BOLD require brief descriptions.

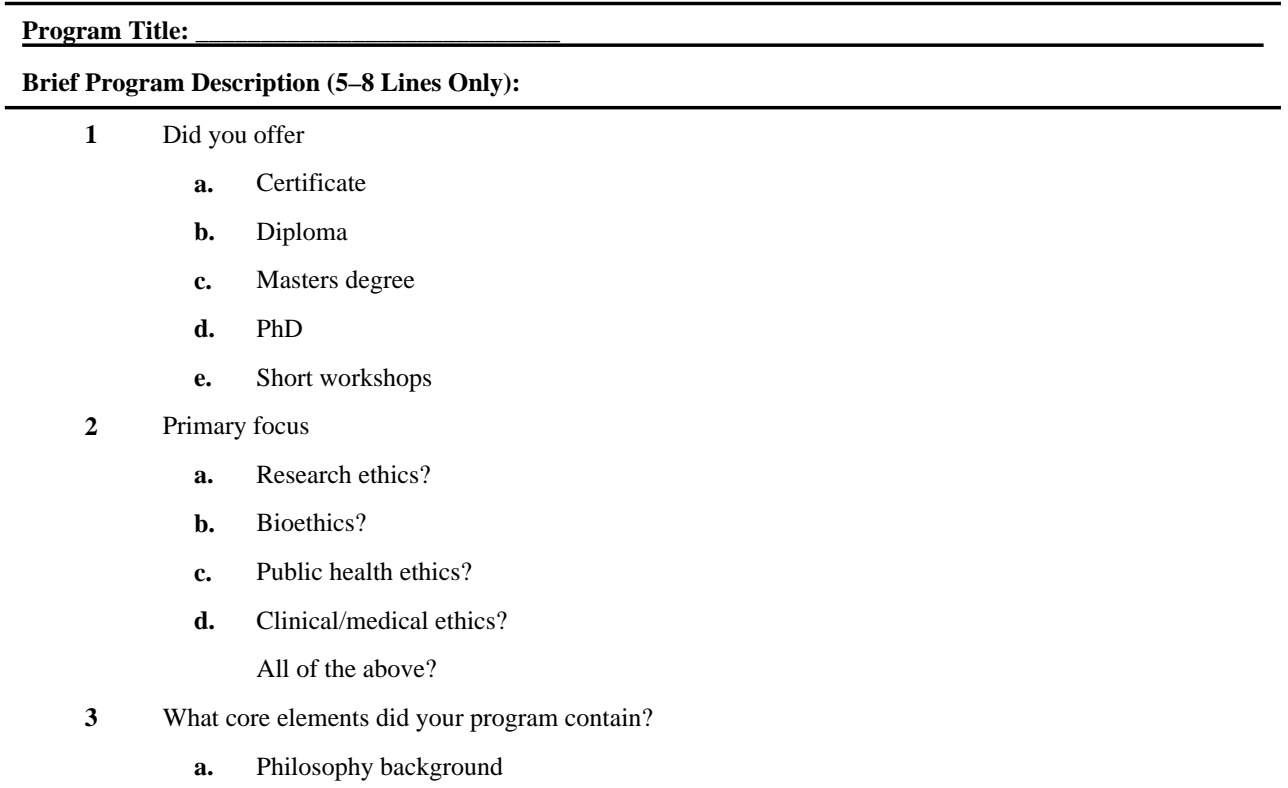




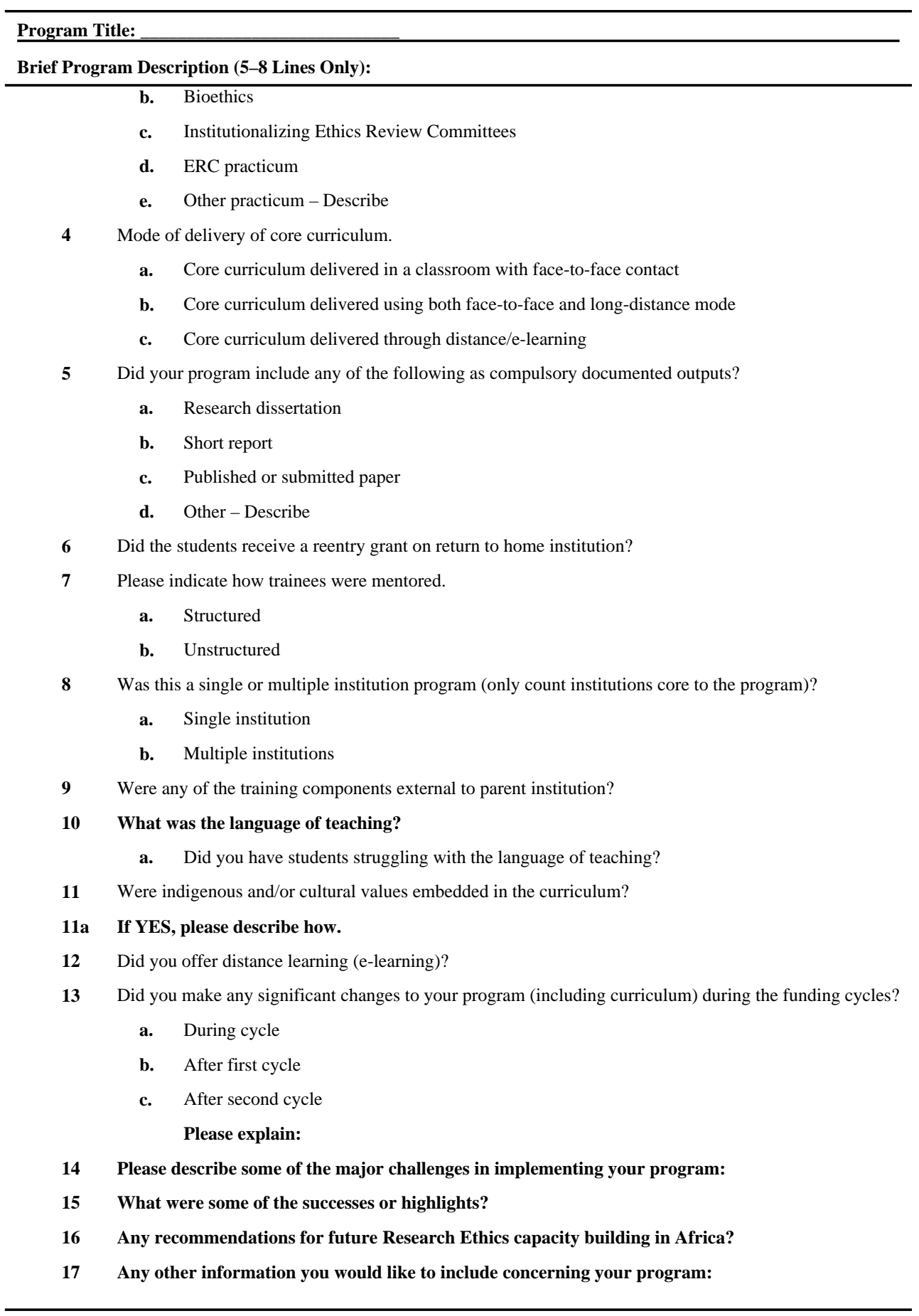




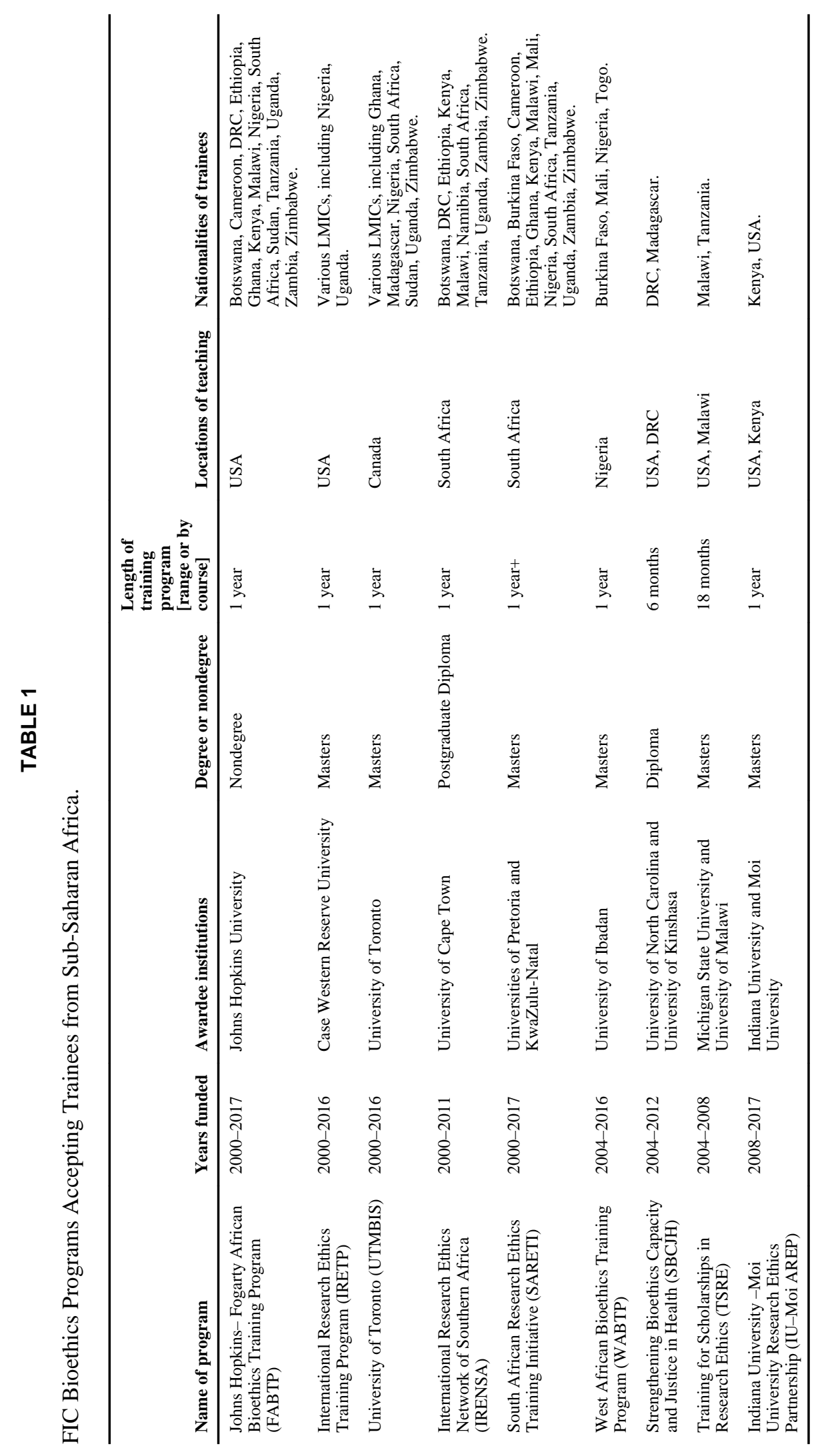

J Empir Res Hum Res Ethics. Author manuscript; available in PMC 2014 December 30. 


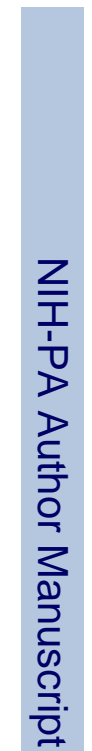



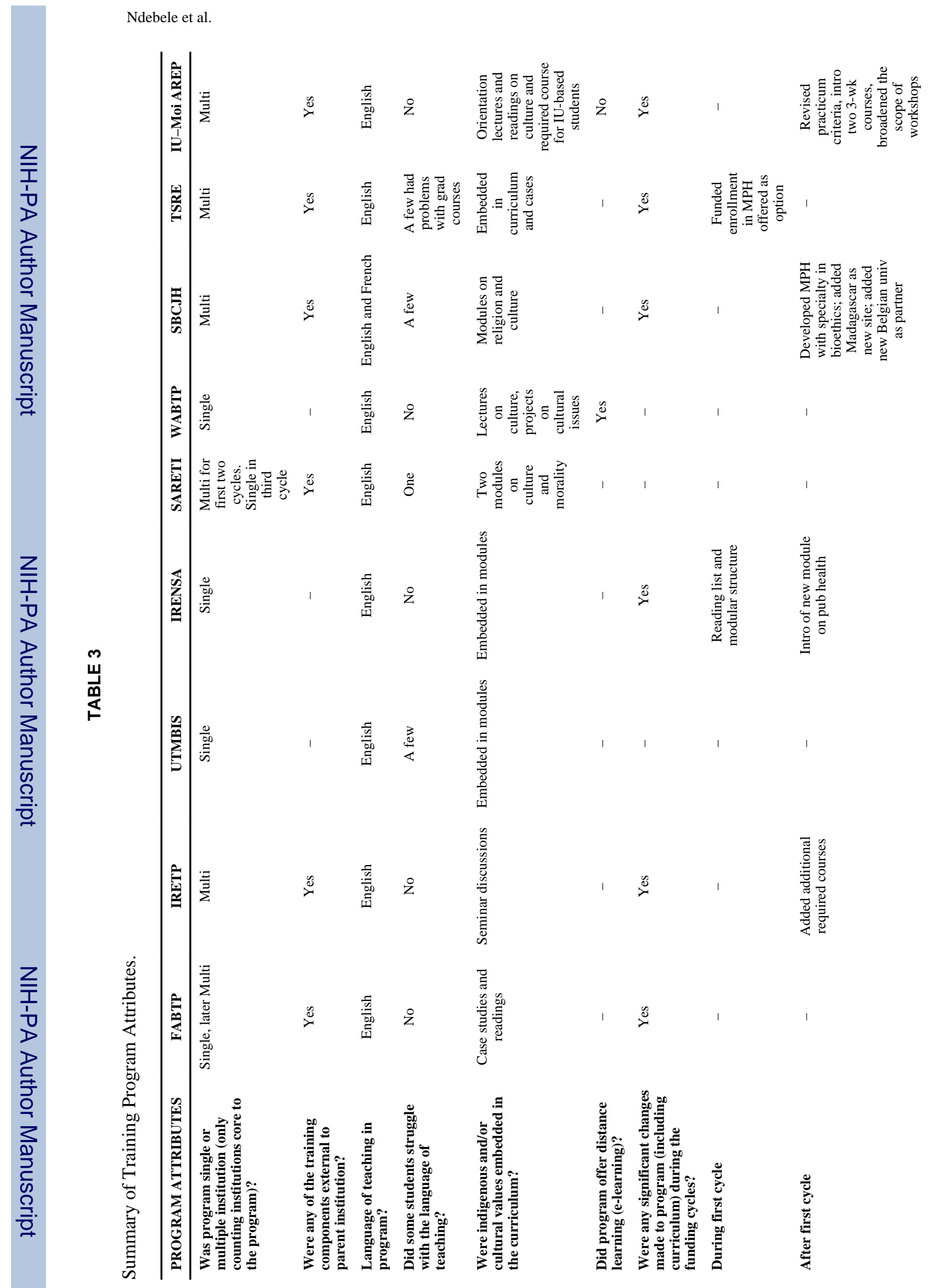

J Empir Res Hum Res Ethics. Author manuscript; available in PMC 2014 December 30. 


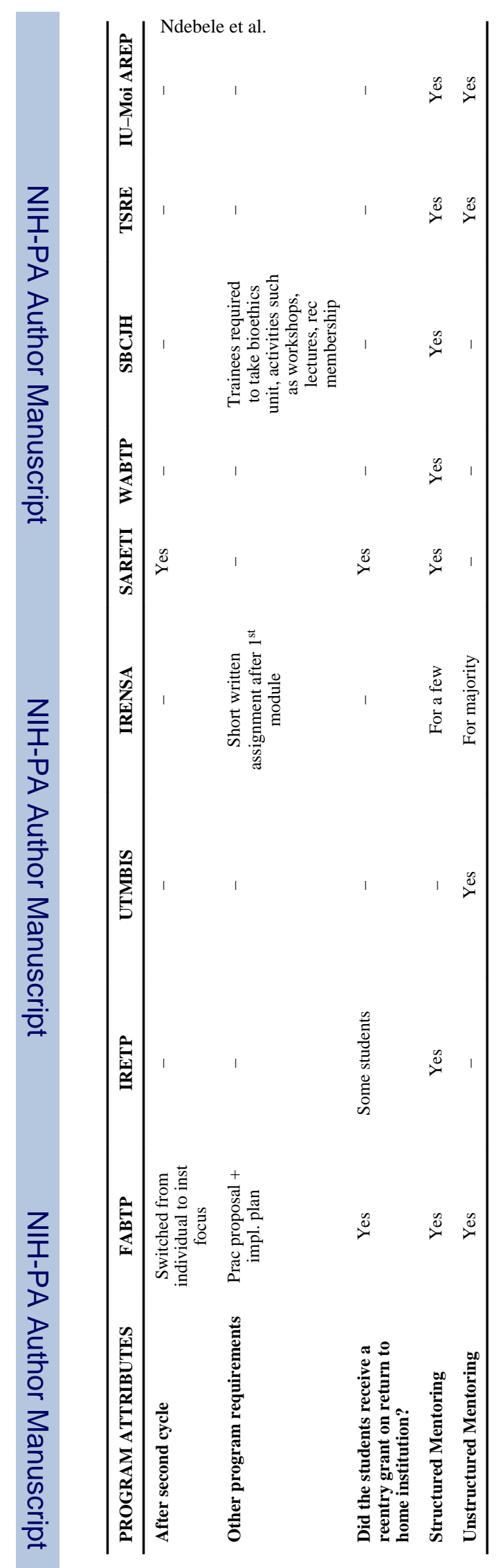

Page 23 


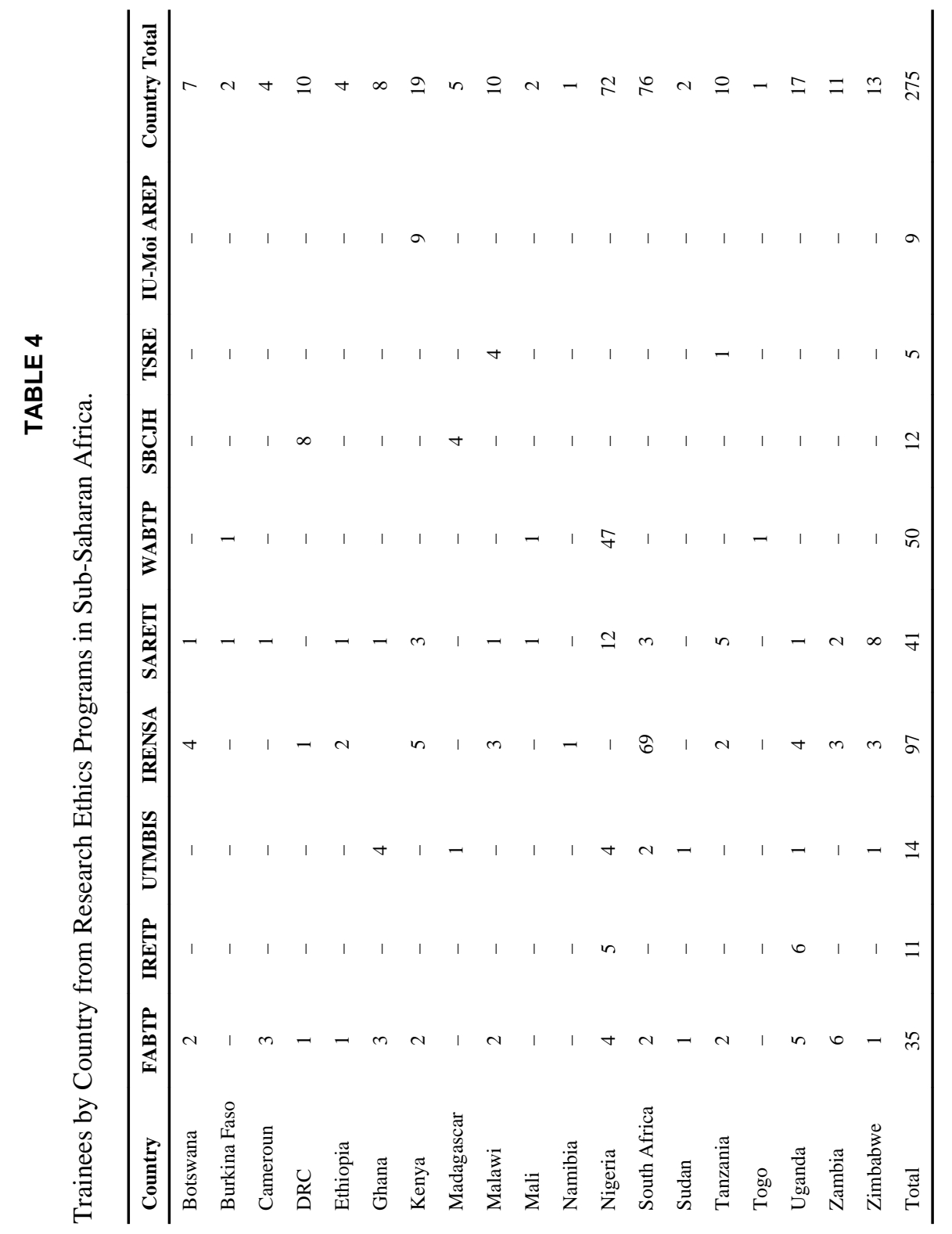

J Empir Res Hum Res Ethics. Author manuscript; available in PMC 2014 December 30. 
